\title{
O SUS como Escola: a responsabilidade social com a atenção à saúde da população e com a aprendizagem dos futuros profissionais de saúde
}

\author{
The Single Health System (SUS) as a School: Social \\ Responsibility Towards the Population's \\ Healthcare and the Education of Future Health \\ Professionals
}

Francisco Eduardo de Campos ${ }^{\mathrm{I}}$

Sigisfredo Luís Brenelli ${ }^{\mathrm{II}}$

Luiz Carlos Lobo ${ }^{\text {III }}$

Ana Estela Haddad ${ }^{\mathrm{IV}}$

O sistema educacional esteve por muito tempo centrado na atividade do professor, considerado o agente ativo do processo ensino-aprendizagem. Neste contexto, é ele quem define e programa o que o aluno vai aprender, como e quando. O foco no ensino, em contraponto ao foco na aprendizagem, determina, assim, a carga horária do curso, oportunidades de aprendizagem, esquema de aulas e avaliação, num programa fechado.

Mas o aprender não é passivo. Não há apenas uma realidade, pois cada um apreende um fato, uma situação, de acordo com sua disponibilidade de perceber e a transforma segundo seu repertório de conhecimentos prévios, vivências e motivação para aprender determinada matéria.

Para aprender, há que elaborar, transformar, integrar o novo conhecimento a estruturas prévias, ou seja, há que ser ativo. Para dar consequência a este conceito, propõe-se mudar o enfoque do sistema educacional a fim de enfatizar o aprendizado do aluno, não mais apenas o ensino.

Paralelamente a essa necessidade de transformação, vivenciamos mudanças na sociedade. O ensino na área da saúde, tradicionalmente centrado nas doenças e usando como insumos para o saber os "indigentes" dos hospitais públicos e Santas Casas, transita para uma nova realidade. Nesta, o indivíduo ganha a condição de cidadão, e a reforma sanitária culmina, por meio de uma "constituição cidadã", com a criação do SUS.

O professor não é mais o centro do processo pedagógico, seu saber não émais suficiente para as necessidades biopsicossociais, que requerem ações e intervenções que considerem um contexto ampliado. A doença como estrutura fundamental do processo de aprendizado passa a ser substituída pela saúde.

A geração de conhecimento, responsável pelo avanço biológico no campo da saúde e que foi a grande responsável pela revolução na ciência médica do século 20, não é suficiente para resolver as demandas da atenção primária e melhorar sua resolubilidade. Essa matriz gerada pelo conhecimento cartesiano precisa ser ampliada, e, assim, surge mais um desafio aos professores da área da saúde: valorizar, incentivar e aperfeiçoar a pesquisa clínica.

\footnotetext{
${ }^{I}$ Ministério da Saúde. Secretaria de Gestão do Trabalho e da Educação na Saúde, Brasília, Brasil; Universidade Federal de Minas Gerais, Belo Horizonte, Brasil.

II Ministério da saúde. Secretaria de Gestão do Trabalho e da Educação na Saúde, Departamento de Gestão da Educação na Saúde, Brasília, Brasil; Universidade Estadual de Campinas, Campinas, Brasil.

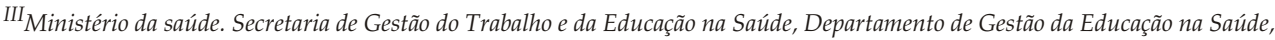
Brasília, Brasil.

${ }^{I V}$ Ministério da saúde. Secretaria de Gestão do Trabalho e da Educação na Saúde, Departamento de Gestão da Educação na Saúde, Brasília, Brasil; Universidade de São Paulo, São Paulo, SP, Brasil.
} 
A Estratégia de Saúde da Família do Ministério da Saúde trouxe uma importantíssima contribuição na estruturação de serviços de saúde do País ao deixar o conceito de assistência, socialmente irresponsável, pois restringe essa responsabilidade a quem procura esses serviços, para enfatizar o conceito de cobertura, definindo a aceitação de uma responsabilidade social - a oferta de ações de saúde voltadas a atender as necessidades e demandas de uma população definida no território. Passa de uma postura reativa para uma postura proativa.

AEstratégia de Saúde da Família é um salto conceitual genuíno, uma transição paradigmática que vem sendo enfrentada pelos idealizadores e gestores da saúde, ao aliar os princípios do Sistema Único de Saúde - integralidade, equidade, universalidade, descentralização, hierarquização, comando único e participação popular -aos princípios da atenção primária: atenção ao primeiro contato/acessibilidade, integralidade, longitudinalidade, coordenação, abordagem familiar, orientação comunitária, competência cultural.

Os profissionais de Saúde da Família, ao atenderem o paciente na própria unidade, e também na casa dele, conhecendo seu contexto social, cultural e econômico, permitindo que o paciente discuta sua enfermidade e entenda as ações propostas para promover, proteger e recuperar sua saúde, devolvem a cidadania desse indivíduo, agora partícipe dessas ações, e que havia sido retirada quando internado em um hospital onde passava a ser mais um caso!

Comunicar-se com um indivíduo, frequentemente com outro nível de escolaridade e conhecimento, despir-se da sua posição, ainda que reconhecendo a grande assimetria da informação que detém em relação a esse paciente, é tarefa das mais difíceis, que dignifica e enriquece a experiência de vida de toda a equipe de saúde.

Da mesma forma que admitimos que o sistema de saúde centrado no conceito passivo de assistência é socialmente irresponsável, pois assume como responsabilidade atender apenas a quem o procura, a educação centrada no professor também pode ser considerada socialmente irresponsável, uma vez que o professor restringe sua missão a ensinar e deixa de ir além e de se comprometer, de fato, com o aprendizado do aluno.

Assumir que a Estratégia de Saúde da Família seja uma fronteira do conhecimento, de inovação na gestão, um ambiente de constante criação e adaptação de tecnologias de atenção à saúde nos ajuda a entender melhor qual deve ser o papel da Universidade Aberta do SUS (UnA-SUS). Para atender às demandas prementes de melhorar a assistência à saúde da população mediante maior capacitação dos profissionais, redes de aprendizado que envolvam a academia e os serviços deverão ser articuladas. Um programa educacional à distância centrado no aluno deverá reconhecer a possibilidade de um currículo flexível - considerado como a soma das oportunidades de aprendizagem oferecidas pela escola com determinado objetivo -, deverá oferecer vários formatos de apresentação da matéria e, sobretudo, admitir um aprendizado assíncrono num grupo de alunos. Além das ferramentas para a troca de informações acadêmicas dos profissionais-estudantes, é preciso desenvolver plataformas para gestão acadêmica da trajetória de cada aprendiz. 